\title{
A critique of the Indian government's response to the COVID-19 pandemic
}

\author{
Jayati Ghosh ${ }^{1}$
}

Received: 30 May 2020 / Revised: 2 July 2020 / Accepted: 3 July 2020 / Published online: 11 July 2020 (c) Associazione Amici di Economia e Politica Industriale 2020

\begin{abstract}
The most destructive effects of Covid-19 in India have not been the result of the disease, but the nature of the government response. The most stringent lockdown in the world destroyed the economy and forced millions into poverty and hunger, but did not control virus transmission. The resurgence of disease as restrictions were lifted and the continued economic distress point to ten major features of state response that ensured these unfortunate outcomes.
\end{abstract}

Keywords Covid-19 $\cdot$ Health $\cdot$ Macroeconomic policies $\cdot$ Livelihoods $\cdot$ Poverty

JEL Classification E2 $\cdot \mathrm{I} 1 \cdot \mathrm{I} 3 \cdot \mathrm{O} 5$

The COVID-19 pandemic unleashed a dramatic economic collapse and humanitarian catastrophe in India. However, the most destructive outcomes did not result from the trajectory of the disease, but from the nature of the government response. Early into the pandemic, the Indian government imposed a national lockdown that was the most stringent in the world, ${ }^{1}$ with curfew-like regulations confining people to their homes, preventing most economic activity and prohibiting movement other than for limited specified tasks. This draconian closure delayed the virus transmission but did not control it. At the start of the lockdown on 25 March the country had only 320 cases (mostly confined to a few regions) and ten deaths from COVID-19 in a population of more than 1.3 billion. By the end of June, India had become the third worst-affected country in the world, just behind the United States and Brazil

\footnotetext{
1 The University of Oxford's COVID19 Government Response Tracker generates a Stringency Index, based on 17 indicators, that gave India a score of 100 out of 100. https://www.bsg.ox.ac.uk/research/resea rch-projects/coronavirus-government-response-tracker.

Jayati Ghosh

jayatijnu@gmail.com

1 Jawaharlal Nehru University, New Delhi, India
} 


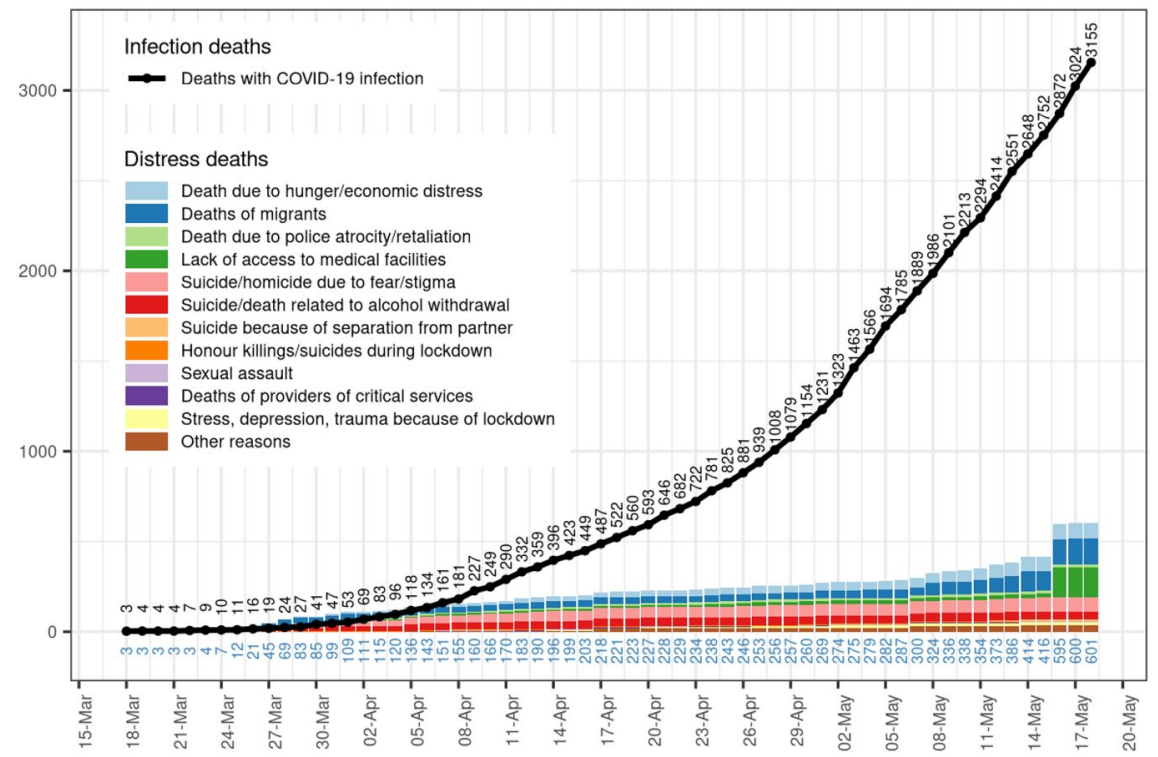

Source: http://coronapolicyimpact.org, last accessed on 27 May 2020

Fig. 1 Deaths from COVID-19 and from distress related to containment policies (15 March to 18 May 2020)

and on course to overtake them with around 20,000 new cases reported every day. There were more than 550,000 confirmed cases of COVID-19, with a death toll of around 17,000 (both numbers likely underestimates, because of low testing rates and late reporting/misreporting of COVID-19 deaths). The disease continues to spread exponentially. ${ }^{2}$

India currently seems to be caught in the worst of both outcomes: inability to control the disease, combined with immense economic losses and massive human tragedies resulting from the lockdown and associated collapse of employment and livelihoods. While COVID-19 deaths have continued to increase, unnecessary deaths resulting from the lockdown have also grown, with at least 600 such death reported by late May (Fig. 1). These include at least 12 deaths resulting from policy brutality on those deemed to have violated lockdown restrictions and a growing number of deaths of migrant workers attempting to reach their homes in difficult circumstances. ${ }^{3}$

\footnotetext{
${ }^{2}$ While the pandemic was largely controlled in some states (notably Kerala, where it was first detected in India) other states like Maharashtra, Delhi and Gujarat had become hotspots, and there was proliferation across the country to states with even worse health infrastructure like Uttar Pradesh and Bihar.

3 https://m.hindustantimes.com/india-news/police-excesses-for-lockdown-violation-led-to-12-death s-study/story-qj5dZ68nxPBc3B0HbSBg3L_amp.html?_twitter_impression=true. However, these numbers are also probably underestimates as they do not include the deaths of at least 80 people travelling on special workers' trains.
} 
The extent of economic devastation is unprecedented in modern Indian history: a generalised cessation of most economic activity in a country in which around $95 \%$ of all workers are informal, without access to any legal or social protection that could provide some income during the period of lockdown. The economy was already slowing down to near-recession before the virus outbreak: GDP growth had fallen to $4.2 \%$ to the year ending 31 March 2020, and 3.1\% in January-March 2020. Thereafter the economy contracted sharply. Although accurate data are still not available, the decline in the April-June quarter has been estimated at anywhere between 3\% (Moody's ${ }^{4}$ ) and $45 \%$ (Goldman Sachs ${ }^{5}$ ). For year as a whole, even the usually more optimistic IMF has estimated a decline of around $4.5 \%$.

Source: http://coronapolicyimpact.org, last accessed on 27 May 2020.

As in most other countries, the lockdown dealt a massive blow to both demand and supply-but with even greater effects on employment. Around 120 million jobs were lost in April alone (Vyas 2020). The greater part of the non-agricultural work force simply had no livelihood for at least 2 months, with no choice but to fall back on existing savings or borrowing for survival. The worst affected were migrant workers (estimated to be around 100-150 million in number). The slight revival in employment in May, as lockdown restrictions were eased somewhat, was not matched by equivalent wage incomes, as wages and self-employed incomes remained much lower than before.

What explains this unfortunate combination of failure to control the pandemic along with extreme economic distress? Ten features of the Indian government's policy response can be identified in this regard:

- The unthinking adoption of containment strategies not suited to the Indian context;

- Excessive centralisation and top-down control, without co-ordination between central and state governments;

- Inadequate investment in and preparation of health systems, facilities and personnel;

- Misplaced timing and delayed responses in several critical areas;

- Parsimony of the relief measures, despite inflated declarations about the official packages;

- Inadequate government spending to increase demand to counter the collapse in economic activity;

- Misplaced focus on measures to increase liquidity;

- Further privatisation of state assets and relaxation of regulations relating to land, labour and environment;

- Class, caste and gender biases of the policy responses; and.

- Suppression of democratic rights and crackdown on dissent during the lockdown.

\footnotetext{
4 https:/economictimes.indiatimes.com/news/economy/indicators/indias-gdp-to-contract-3-1-in-2020moodys/articleshow/76515744.cms.

5 https://www.livemint.com/news/india/indian-economy-may-contract-by-45-in-june-quarter-goldmansachs-11589728732340.html.
} 


\section{Lockdown as the only containment strategy}

In dealing with the pandemic, many countries followed the pattern observed in Wuhan, China, involving strict lockdowns, controls on mobility, economic and social activity and requirements of "social distancing" (hereafter referred to more correctly as physical distancing). In India, a very stringent version of this strategy was adopted relatively early in the onset of the infection, and also very abruptly, with only four hours' notice given to the population. Unfortunately, this failed to take into account the specific socio-economic contexts and characteristics of life and work for most people in India, which made the consequences of this strategy both more damaging and less effective.

Around $95 \%$ of all workers in India are informal, with no legal protection vis-àvis their employers and also little or no social protection. Around half of all workers are self-employed, usually in informal micro-enterprises. All such workers were immediately and sharply affected by the lockdown, which deprived them of paid employment without warning. Since many of these workers already operate at the margin of subsistence, this generated severe economic distress, made worse by the fact that there was very little public assistance to prevent growing destitution and hunger. This made them more vulnerable to all diseases, including COVID-19, worsening health conditions overall.

Further, around one-third of the urban population and at least quarter of villagers live in extremely crowded and congested conditions, in very small dwellings with five or more people confined to one room. "Stay-at-home" policies in such contexts are unreasonable, oppressive and even counterproductive. Physical distancing norms cannot be effectively followed, especially for prolonged periods. Requirements like frequent and prolonged washing of hands with soap cannot be met where access to clean water is limited and it must be collected and stored, often through lengthy and arduous journeys made by women and girls. All these aspects became more difficult as the lockdown continued, as declining incomes forced many people to cut back on spending for even essential items. But there were no official guidelines for people in these conditions to protect themselves from the virus.

\section{Centralisation without co-ordination}

The centralisation of power by the Union Government during the pandemic was rapid. The lockdown was imposed by invoking the Disaster Management Act 2005, which allows the central government and the National Disaster Management Authority to over-ride any other law in force and issue directions to any authority in India, and requires that all such directions must be followed. However, the centre did not use these additional powers to increase co-ordination; rather, it imposed often changing and sometimes contradictory decisions upon state governments without consulting them - including on the national lockdown, which they got no time to prepare for. Subsequently, specific requests and concerns were ignored or brushed 
aside, ${ }^{6}$ leading to avoidable delays and shortages. Lack of consultation and co-ordination with states generated other types of confusion, especially evident in interstate movement of trains and buses, which led to chaos and long delays and unnecessary detours. Similarly, air travel was suddenly allowed by the central government a week before the official end of the national lockdown on 31 May, again without consulting states. This created chaos, with many flight cancellations as some states refused permission for flights to land and others insisted in quarantine requirements that the centre had lifted on its own.

Fiscal centralisation had even worse consequences. State governments were made responsible for essential public health measures and dealing with economic effects of the lockdown, but they were completely strapped for cash. The central government provided almost nothing by way of additional resources and imposed many conditions on their ability to borrow, thereby limiting their ability to spend and effectiveness in dealing with the disease and the economic distress.

\section{Timing and delays}

The lockdown was abruptly imposed when there were relatively few COVID-19 positive cases, mostly confined to very specific regions and hotspots. Nevertheless, it extended over the entire country, across all states and covering both urban and rural areas, stopping all transport and all economic and social activity other than some defined essential services. The most extreme weapon that could be used against the pandemic was used first, with no strategy in reserve in case the virus continued to spread. Eventually, when such an aggressive lockdown became unsustainable because of the impact on the economy and livelihoods, the government was forced to lift restrictions precisely when it had become more dangerous to do so, because of prevalence of the disease and therefore greater chances of infection.

Delays in official response were especially damaging for migrant workers in different parts of the country, many of whom were stranded without income and faced destitution and hunger as their savings ran out. Surveys of migrant workers after 1 month of lockdown found that most of them (96\%) had not received food rations or cash relief from the government, while around $90 \%$ had not been paid for the period by their employers either (SWAN Report 2020). In the initial phase, all movement of people was prohibited, so they could not return to their homes; thereafter, material distress forced people to travel by foot over long distances for want of any alternative. The central government took a month to allow interstate movement of migrants in buses, and even those were to be arranged and paid for by the state governments. Special train services for migrants were started even later and required travellers

\footnotetext{
${ }^{6}$ For example, states that were sourcing testing kits from within and outside the country were told to desist and wait for the centrally-approved kits, to be imported from China. When these eventually gave inaccurate results, the states were asked to stop using them and return the unused testing kits. https:// economictimes.indiatimes.com/industry/healthcare/biotech/pharmaceuticals/centre-decides-to-withd raw-faulty-covid-19-antibody-test-kits-cancels-import-orders-from-china/articleshow/75406955. $\mathrm{cms}$ ?from $=\mathrm{mdr}$.
} 
to pay full fares even though most were already greatly impoverished because of the lockdown. Such delays in providing adequate and accessible transport facilities added to distress and led to wider transmission of the virus. The millions of migrant workers who were forced to congregate in stations to try and find their way home or had to walk hundreds of kilometres, arrived enervated and exhausted, with greater chances of exposure to the virus and likelihood of spreading infection at their destinations.

\section{Inadequate preparation of the health system}

The purpose of a lockdown is not to completely suppress or eradicate the virus (which it cannot do) but to buy time. Since it delays the spread of the virus, it allows the government to take measures to deal more effectively with the pandemic once the lockdown is lifted. These measures include: expanding, training and deploying the public health force; ramping up testing capacity and availability; developing a clear plan to trace and quarantine contacts; and ensuring key facilities (including hospital beds and intensive care units, ventilators and other machines, personal protective equipment for health care workers) to treat and isolate patients. However, the central government's actions on these fronts were limited, and extremely inadequate for the purpose. In some cases, it even thwarted or made more difficult the efforts of state governments. Very limited funds (less than $0.04 \%$ of GDP) were made available for immediate public health expenditure (CBGA 2020) and less than half of that was distributed among states, in a rather arbitrary manner. Other than for a few states like Kerala, most state governments did not use the lockdown period effectively to identify infected individuals through testing, and then to trace their contacts and quarantine them to reduce transmission. Testing increased slowly: on 3 May the testing rate (758 per million) was not even double the rate just before the lockdown. By late June the testing rate had increased to 5371 per million, but still remained low relative to most comparator countries, with high prices of tests deterring many. Supplies of basic equipment like protective equipment for health workers were not organised in a timely manner, and shortages in these emerged quickly as the disease spread. Other facilities like hospital beds, ventilators, etc., also remained well below the need.

Meanwhile, the single-minded focus on COVID-19 had other adverse health implications, as other diseases and their treatment were ignored or given less attention. Many TB patients did not receive the required treatment; immunisation of children suffered because of the lockdown; cancer patients and those requiring dialysis suffered neglect; important operations have been indefinitely postponed for large numbers of people; and there were $40 \%$ fewer institutional deliveries of babies duringthe lockdown than in the same period of the previous year. ${ }^{7}$

\footnotetext{
7 https://www.hindustantimes.com/india-news/during-lockdown-births-at-clinics-plummet-by-40/story -D1DzxlaZhGswBRtHbeXwjN.html.
} 


\section{Parsimony of stimulus and relief packages}

Despite sharp declines in wage incomes and self-employed livelihoods, official relief was minuscule. It has been widely noted (see Ray and Subramaniam 2020) that despite a wide range of feasible policy proposals that could be speedily implemented within the existing institutional framework, the central government has exhibited extreme parsimony. The first relief package announced after the lockdown included many items that were already committed public spending: additional expenditure amounted to only around $0.5 \%$ of GDP. Six weeks into the lockdown, the Prime Minister announced another package supposedly equivalent to $10 \%$ of GDP, but the details showed that much of this was in the form of credit guarantees and other liquidity provision that did not require additional fiscal outlay. Total additional public spending promised by all the relief measures announced by the end of May amounted to only around 1\% of GDP (CBGA 2020), and much of this had not yet reached people.

The inexplicable delay in distributing food grain from the public distribution system to the hungry caused particular harm. Before the lockdown, the central government (through the Food Corporation of India or FCI) held around 77 million tonnes of foodgrain, more than three times the buffer stock requirement. There was a very limited free distribution of additional foodgrain to those covered by the National Food Security Act, but even a month later only 2.2 million tonnes of this had been distributed to states. At the same time, the government sold some stocks in the open market, at a loss (Rawal et al. 2020). Since more wheat was being procured from farmers just after the harvest, the public stocks increased to more than 100 million tonnes by the beginning of June, which meant that some of the stock effectively rotted in the storage facilities. A popular demand to distribute $10 \mathrm{~kg}$ of free grain per month to $80 \%$ of the population, which is still eminently feasible, was ignored.

In the event, the major source of relief for informal workers was the rural employment guarantee, (on the basis of a law enacted in 2005, which promises 100 days of work per rural household at a national wage). But in April 2020, employment in this programme fell by $83 \%$ relative to the previous year, largely because of confusion about the lockdown. Subsequently, the central government increased the budgetary allocation by $65 \%$, but this simply brought it to levels required to meet the pre-pandemic demand. Legally speaking, the allocations cannot be a constraint on spending: this is a demand-driven programme for which funds must be provided by law, so the likely increase in demand for work should be met with commensurate increases in central government funding.

\section{Lack of demand stimulus}

The inadequate spending on relief reflects a wider constraint on the overall macroeconomic stance. This has implications for economic activity well beyond the period of the pandemic. Projections of GDP in the current fiscal year (1 April 2020 to 31 March 2021) anticipate declines of between 5 and 20\% of GDP. The eventual 
outcome will depend on the duration, severity and spread of the pandemic, as well as the length and severity of the lockdown measures and especially the government's macroeconomic responses. The lockdown's adverse impact on incomes, especially in the non-farm sector, generate negative multiplier effects that will fester for a while and affect both household and private corporate spending. Therefore, the government must counter the decline in aggregate demand by increasing its own spending: directly by providing food and incomes to the poor and indirectly by enabling the revival of micro, small and medium enterprises that employ the bulk of the workforce. This requires increased public expenditure of fairly large amounts, if only to counter the declines in spending elsewhere.

However, the Indian policy response thus far has been characterised by extreme fiscal rectitude, with a reluctance to increase public spending beyond relatively trivial amounts that are unlikely to do much to prevent rapid declines in economic activity. Some of this stems from concerns about having a large fiscal deficit, which would supposedly impact on "investor confidence". This is a false premise, since as GDP declines, tax revenues also decline and therefore fiscal deficits would rise even with the same unchanged or even reduced level of public expenditure. Indeed, there is evidence that this is what happened in the previous fiscal year (Chandrasekhar and Ghosh 2020). By contrast, if increased public spending generates a revival of economic activity, that would cause tax revenues also to increase, and could even lead to a decline in the fiscal deficit to GDP ratio as the denominator increases. However, the policy straitjacket that the Indian government seems to have created for itself thus far has prevented such obviously necessary public spending.

Even as the central government is not spending enough to drag the economy out of a major recession, it is preventing the state governments from doing so. State governments were starved of resources even before COVID-19 struck and are still owed around significant amounts by the Centre. ${ }^{8}$ Because of the collapse in economic activity due to lockdown, their tax revenues in April 2020 were down to as little as one-tenth of the collections in April 2019. Unlike the central government, state governments in India have a hard budget constraint, so they cannot run deficits at will. There are constraints and conditions imposed on their borrowing, which make it near impossible for them to increase overall spending in the face of significantly declining revenues. Therefore, without a major policy change, the aggregate fiscal stance is likely to be negative over the entire year, adding to the recessionary forces in the economy.

\section{Focus on liquidity and supply side measures}

In the absence of an expansionary fiscal stance, the government has relied heavily on measures aimed at increasing liquidity in the economy: using the central bank to provide credit guarantees and access to loans at slightly lowered rates to banks,

\footnotetext{
8 Under the Goods and Services Tax law, states were guaranteed to be paid for any loss of revenue for the first five years of the GST implementation, which came into force on 1 July 2017. GST revenues were supposed to increase by $14 \%$ per year; any shortfall from this would be met by the Central government, which has unfortunately not honoured this promise fully.
} 
non-bank financial companies and all sizes of business. Credit systems in India were already stressed before the pandemic, and in dire need of financial assistance. But such measures cannot be effective on their own in the current crisis. In a context of declining demand, access to credit will not be sufficient to increase investment. Banks and non-banks are more likely to use the cheaper funds to repair their balance sheets than to lend to borrowers who may eventually be unable to repay. To the extent that increased credit provision culminates in eventual default because of worsening economic conditions, this would only accentuate the crisis. A more promising use of central banks funds would be to underwrite central and state government debts, monetise the central government deficit and allow the state governments to borrow at the repo rate (lowest central bank rate) so as to enable more public spending.

Such increased spending would not be inflationary if measures are simultaneously taken to increase supply. Currently, the supply-side measures proposed by the government are far too general and do not take into account the specific circumstances created by the pandemic and lockdown, which stopped production of many goods and services. The revival of economic activity-and ensuring a continuous supply of essential goods and services and items of mass consumption to prevent specific shortages and associated price rises-requires a planning framework in which central and state government co-ordinate their interventions. However, such a framework seems to be entirely absent at present.

\section{Pushing more neoliberal reforms}

A major part of the policy response of the central government has been directed to medium term "structural" reforms that bear no immediate relation either to the pandemic or to the economic havoc created by the lockdown. Indeed, the most crucial systemic requirement - that of substantially increased spending on public health and the care economy-was not given any significance. Instead, a range of neoliberal reforms harking to the well-known tropes of privatisation and deregulation were introduced, which would have very little immediate effect on economic revival, and could possibly damage the economy in the medium term. These include: deregulation of agricultural markets, which could expose farmers to the whims of monopsonistic corporate buyers rather than empowering them; encouragingmore fossil fuel extraction, especially in the coal sector, which could add to future problems of climate change and inadequate adaptation; reducing environmental regulations in order to attract private investors, which could damage the ecology; privatising public sector enterprises that could have played an important role in economic revival; opening up banking and retail trade to foreign investors; and even suggesting private involvement in space exploration!

While many of these measures can be considered and critiqued separately, it was also evident that the government was using the opportunity created by the pandemic to push through "reforms" that would alter the relative power of big capital to labour and to other groups in society. This was especially evident in the move by several 
state governments to suspend or do away with many laws designed to protect labour, on the argument that this would help to attract foreign capital. ${ }^{9}$

\section{Caste, class and gender bias of policy responses}

Policy responses to COVID-19 were based on and intensified existing inequalities of class, caste and gender. The class divide was most evident in the prevention measures that were imposed on the population, as noted above, since these presumed living conditions available only to middle classes and elites, and could not be implemented among the urban poor and many rural dwellers. The denial of livelihood to informal workers without providing compensatory social protection was another indication of the class orientation of policy. The refusal to release foodgrain for the hungry even as grains accumulated in public storage facilities was compounded by the obscenity of releasing some stock to convert into ethanol for making hand sanitisers. The starkest examples of unequal treatment came from controls on mobility and subsequent provision of transport to migrants. Throughout the period of lockdown, incoming evacuation flights were arranged (often at public expense) for Indian citizens stranded abroad, who are typically among the better-off. However, stranded workers in India got little or no assistance. At first movement was completely prohibited, and those who desperately attempted to walk hundred of kilometres to their homes were detained, attacked and humiliated in various ways for "breaking the curfew". When some trains for internal migrants were finally arranged, impoverished workers were made to pay full fares, and conditions on these trains were often appalling, with prolonged and delayed journeys in intense heat during which food and water were not provided, adding to distress and ill-health. Between 9 and 27 May there were 80 deaths on board such trains for stranded migrant workers. ${ }^{10}$

The still pervasive caste system in India justifies hierarchies and discrimination, and also relies on "social distancing", which became a natural fit in the current pandemic for those on top of the social hierarchy. This added further layers to the impact of pervasive patriarchy. Many of the frontline workers in the fight against COVID19 , especially basic health workers and sanitation workers, come from lower castes and tend to be women. They are poorly remunerated, often not even receiving minimum wages. During the pandemic, they have typically had to work without adequate protection (with a disproportionate number getting infected) faced social discrimination and physical threats, and in many cases have not even received their full pay. Meanwhile, surveys have found that the impact of job losses and food insecurity has been significantly higher for women, as well as for Muslims and Dalits (e.g., Lahoti

\footnotetext{
9 https://www.bloombergquint.com/coronavirus-outbreak/covid-19-response-will-states-diluting-labou r-laws-attract-more-investment.

$10 \mathrm{https} / / / \mathrm{www}$.hindustantimes.com/india-news/railway-protection-force-reports-80-deaths-on-shramiktrains/story-psJ13EenY4B0uUYMRvkChL.html.
} 
et al. 2020). As in many other countries, the lockdown was also associated with significant increases in complaints of domestic violence on women. ${ }^{11}$

\section{Suppression of democratic rights and crackdown on dissenters}

Just before the lockdown, there were many peaceful protests across the country, against the attempt a new citizenship law that would effectively give lower status to Muslims. Some of these had been met with violence on the part of police and armed supporters of the ruling party. The central government used the opportunity presented by the lockdown not just to prohibit any kind of public protest but to arrest several of those who had participated in peaceful protests, while protecting supporters of the ruling party. The crackdown on dissent has affected students, lawyers, human rights activists, journalists and academics, many of whom are being forced into prisons where COVID-19 infections are rising. The purpose of such continued repression during a period of national calamity appears to be to teach a lesson to those who had interrogated the government's intentions and actions; and to intimidate others. Unfortunately, this also means that the government's own ability to create a widespread social consensus and atmosphere of trust in which to combat the pandemic is correspondingly reduced.

\section{Conclusion}

The Indian experience of COVID-19 has been disastrous even before the disease has reached a peak, and this is largely due to the central government response, which has been wanting in several crucial respects. A major shift in macroeconomic strategy is required to enable the economy and livelihoods to recover eventually, and this must be combined with large increases in the outlays for public health. However, there is currently no evidence that the ruling dispensation is disposed to either of these.

\section{Compliance with ethical standards}

Conflict of interest There are no conflicts of interest involved in this article.

\section{References}

Chandrasekhar, C. P., \& Jayati G. (2020). Economic Contraction and the Fiscal Stance of the Indian Government. MacroScan, BusinessLine 16 June. https://www.networkideas.org/featured-artic les/2020/06/economic-contraction-and-the-fiscal-stance-of-the-indian-government/.

Centre for Budget Governance and Accountability (CBGA). (2020). Numbers on the Edge: Assessing India's Fiscal Response to Covid-19. New Delhi: CBGA.

\footnotetext{
11 Gender blindness was also evident in the exclusion of sanitary napkins from the original list of essential items whose production and distribution was permitted during the lockdown.
} 
Lahoti, R., Basole, A., \& Abraham, R., Kesar, S., \& Nath, P. (2020). Hunger grows as India's lockdown kills jobs. The India Forum 5 June 2020. https:/www.theindiaforum.in/sites/default/files/ pdf/2020/06/05/hunger-grows-as-india-s-lockdown-kills-jobs.pdf.

Stranded Workers Action Network (SWAN). (2020). 21 Days and Counting: COVID-19 Lockdown, Migrant Workers, and the Inadequacy of Welfare Measures in India. Bengaluru, 15 April, https:// www.thehindu.com/news/resources/article31442220.ece/binary/Lockdown-and-Distress_Repor t-by-Stranded-Workers-Action-Network.pdf.

Rawal, V., Kumar, M., Verma, A., \& Pais, J. (2020). COVID-19 Lockdown: Impact on agriculture and the rural economy. SSER Monograph 20/3. New Delhi. Available at https://www.networkideas.org/wpcontent/uploads/2020/06/sserwp2003.pdf. Accessed 1 July 2020.

Ray, D., \& Subramaniam, S. (2020). India's Lockdown: An interim report. 20 May. https://debrajray.com/ wp-content/uploads/2020/05/RaySubramanian.pdf.

Vyas, M. (2020). The jobs bloodbath of April 2020. Centre for Monitoring Indian Economy, 5 May. https ://cmie.com/kommon/bin/sr.php?kall=warticle \&dt=2020-05-05\%2008:22:21\&msec=776. 